\title{
Analisis Image Comments to Image Likes Ratio Pada 5 Brand di Indonesia Yang Sering Dikira Brand Luar Negeri
}

\author{
I Kadek Andi Suarjayasa \\ STIMIK STIKOM Indonesia \\ andisuarjayasa1@gmail.com
}

\begin{abstract}
Instagram is an American social media app created by Kevin Systrom and Mike Krieger. Instagram lets users create videos lasting 15 seconds to 15 minutes accompanied by music, filters, and some other creative features. In Indonesia there are 59.840 million Instagram users, with that number, 22.6 percent of the population in Indonesia is Instagram users. The rise of the number of Instagram users who are active in Indonesia can certainly provide opportunities for brands to make the Instagram platform as a social media marketing platform. As for the 5 Brands in Indonesia That Are Often Mistaken for Overseas Brands that use Instagram as a marketing platform, namely: J-CO, CFC, Krisbow, Men's Republic, and Polytron. The purpose of this study is to calculate the credibility of the performance of Top 5 Brand Instagram accounts in Indonesia that are often mistaken for overseas brands. The method used for this research is quantitative exploratory methods. The results of this study showed that Brand J-CO Indonesia ranked first and had good account performance credibility.
\end{abstract}

\begin{abstract}
ABSTRAK
Instagram merupakan aplikasi sosial media yang berasal dari Amerika yang dibuat oleh Kevin Systrom dan Mike Krieger. Instagram memungkinkan penggunanya membuat video berdurasi 15 detik sampai dengan 15 menit yang disertai dengan musik, filter, dan beberapa fitur kreatif lainnya. Di Indonesia terdapat 59,840 juta pengguna Instagram, dengan jumlah sebanyak itu maka 22,6 persen penduduk di Indonesia merupakan pengguna Instagram. Maraknya jumlah pengguna Instagram yang aktif di Indonesia tentu dapat memberikan peluang bagi brand untuk menjadikan platform Instagram sebagai platform social media marketing. Adapun 5 Brand di Indonesia Yang Sering Dikira Brand Luar Negeri yang memanfaatkan Instagram sebagai platform marketing, yaitu : J-CO, CFC, Krisbow, Men's Republic, dan Polytron. Tujuan dari penelitian ini yaitu untuk menghitung kredibilitas dari performa akun Instagram Top 5 Brand di Indonesia Yang Sering Dikira Brand Luar Negeri. Metode yang digunakan untuk penelitian ini yaitu metode eksploratif kuantitatif. Hasil dari penelitian ini menunjukan bahwa Brand J-CO Indonesia mendapatkan peringkat pertama dan memiliki kredibilitas performa akun yang baik.
\end{abstract}

Keyword : Social Media Marketing ; Social Media Instagram ; Image Comments to Image Likes Ratio ; Brand Indonesia. 


\section{PENDAHULUAN}

Teknologi informasi dan komunikasi yang telah berkembang dengan pesat mampu menghantarkan manusia untuk menciptakan bentuk baru dalam cara berkomunikasi serta berinteraksi melalui media sosial. Media sosial memberikan pengaruh yang cukup besar, saat ini media sosial diajadikan sarana berkomunikasi dalam setiap aktifitas keseharian bersosial di masyarakat. Komunikasi tidak hanya dapat dilakukan secara fisik, tetapi juga dapat dilakukan dengan menggunakan berbagai aplikasi media sosial di dunia maya. Keunggulan layanan aplikasi sosial media adalah memberikan ruang komunikasi dua arah antara konsumen-perusahaan dan konsumen-konsumen.

Dengan pesatnya perkembangan teknologi media sosial, telah memberikan dampak terhadap situs-situs komunikasi, dari yang awalnya hanya sekedar email dan chatting, saat ini sudah banyak jejaring media sosial yang bisa digunakan sebagai alat komunikasi. Contoh aplikasi sosial media yang memiliki banyak pengguna saat ini yaitu Instagram yang merupakan salah satu fitur yang dimiliki oleh smartphone atau telepon pintar. Instagram merupakan aplikasi handphone yang berbasis Android, selain itu Instagram juga merupakan aplikasi yang digunakan untuk menjepret foto, mengelola foto, mengedit foto, memberi efek filter pada foto dan membagikan foto tersebut kesemua orang.

Instagram sendiri berkembang dari aplikasi iPhone untuk berbagi foto, hingga sekarang menjadi sebuah perusahaan media sosial di Internet yang berkembang. Secara statistik setelah 10 bulan setelah dikeluarkan, Instagram menarik perhatian 7 juta pengguna baru yang telah mengunggah 150 juta foto di Instagram. Sedangkan Instagram sendiri hanya memiliki 5 staf yang bekerja di dalamnya.

Penelitian ini menggunakan metode eksploratif kuantitatif, dan akan menghitung menggunakan rasio-rasio yang ada pada Instagram. Pada penelitian ini dijelaskan bahwa terdapat 14 rasio yang ada pada sosial media Instagram dan relevan digunakan sebagai media ukur kredibilitas akun yang ada. Penelitian ini hanya berfokus untuk menghitung kredibilitas Image Comments to Image likes Ratio pada 5 Brand di Indonesia Yang Sering Dikira Brand Luar Negeri. Tujuan dari penelitian ini adalah mengetahui kredibilitas performa dari akun Instagram 5 Brand di Indonesia Yang Sering Dikira Brand Luar Negeri menggunakan Image Comments to Image likes Ratio. 


\section{METODE PENELITIAN}

Penelitian ini menggunakan metode eksploratif kuantitatif untuk mengetahui kredibilitas dari performa akun Instagram 5 Brand di Indonesia Yang Sering Dikira Brand Luar Negeri. Metode eksploratif merupakan penelitian yang memiliki tujuan untuk melakukan eksplorasi atau memperdalam pengetahuan ataupun ide-ide baru mengenai suatu hal yang baru, guna merumuskan permasalahan secara terperinci (Maryam, Isrok'atun, and Aeni 2016) . Tujuan dari penelitian ini yaitu mengetahui nilai kredibillitas dari performa akun Instagram 5 Brand di Indonesia Yang Sering Dikira Brand Luar Negeri. Ada beberapa langkah yang harus dilakukan dalam penelitian ini, sehingga mampu menemukan peringkat pertama pada akun Instagram 5 Brand di Indonesia Yang Sering Dikira Brand Luar Negeri yang memiliki performa terbaik. Langkah-langkah yang dilakukan pada penelitian ini, diantaranya yaitu :

\section{Melakukan Eksplorasi Pada Website Untuk Menentukan Objek yang Akan Dianalisa.}

Eksplorasi ini dilakukan pada beberapa halaman website yang menyediakan informasi mengenai objek yang akan di teliti. Setelah ekslorasi selesai dilakukan, sehingga ditemukan nama-nama Brand di Indonesia Yang Sering Dikira Brand Luar Negeri yang akan dijadikan objek analisa. Setelah melakukan eksplorasi pada halaman website, maka langkah selanjutnya yaitu mencari nama akun Instagram dari masing-masing Brand. Pastikan semua Brand memiliki akun pada aplikasi sosial media Instagram.

2. Menghitung Nilai Rata-Rata Variable Dari 5 Brand di Indonesia Yang Sering Dikira Brand Luar Negeri.

Pada langkah ini, peneliti menghitung nilai variable Image Comments dan Image Likes. Variabel merupakan sesuatu yang memiliki nilai bervariasi dimana nilai tersebut dapat dijadikan sebagai dasar untuk empat data yang berbeda seperti rasio, skala, ordinal, nominal dan internal (Rankuti 2015) . Untuk menghitung nilai rata-rata dari variabel Image Comments dan Image Likes yaitu dengan cara mengambil minimal 10 postingan terakhir kemudian di hitung sehingga menemukan nilai rata-rata dari masingmasing variabel.

\section{Menghitung Nilai Kredibilitas Rasio}

Untuk menghitung nilai kredibilitas dari Image Comments dan Image Likes ratio, peneliti menggunakan cara membagi nilai variabel pertama dengan nilai variabel kedua. Jika Image comments memiliki nilai 100 dan Image Likes memiliki nilai 300, maka cara menghitungnya yaitu $100: 300=0,3$. Dengan begitu nilai dari Image Comments dan Image Likes ratio adalah 0,3. Dan jika jumlah like tidak dilihatkan maka nilainya bisa dibuat 0 .

\section{Menentukan Peringkat Pada Akun Instagram}

Pada langkah terakhir yang dilakukan pada penelitian ini yaitu menentukan peringkat pada masingmasing rasio yang ada. Pada penentuan peringkat perlu melihat karakteristik dari rasio yang di teliti. Jika karakteristik rasio merupakan rendah, maka objek yang memiliki nilai terendah akan mendapatkan angka 5 dan objek yang memiliki nilai tertinggi akan mendapatkan angka 1. Namun jika rasio memiliki karakteritik tinggi maka objek yang mendapatkan nilai tinggi akan mendapatkan angka 5 dan objek yang mendapatkan nilai terendah akan mendapatkan angka 1. Setelah mendapatkan hasil kredibilitas ratio maka dapat disimpulkan objek yang mana mendapatkan peringkat 1 sampai dengan peringkat 5 . 


\section{HASIL DAN PEMBAHASAN}

Akun Instagram dari 5 brand di Indonesia yang sering dikira brand luar negeri yaitu:

1. J-CO
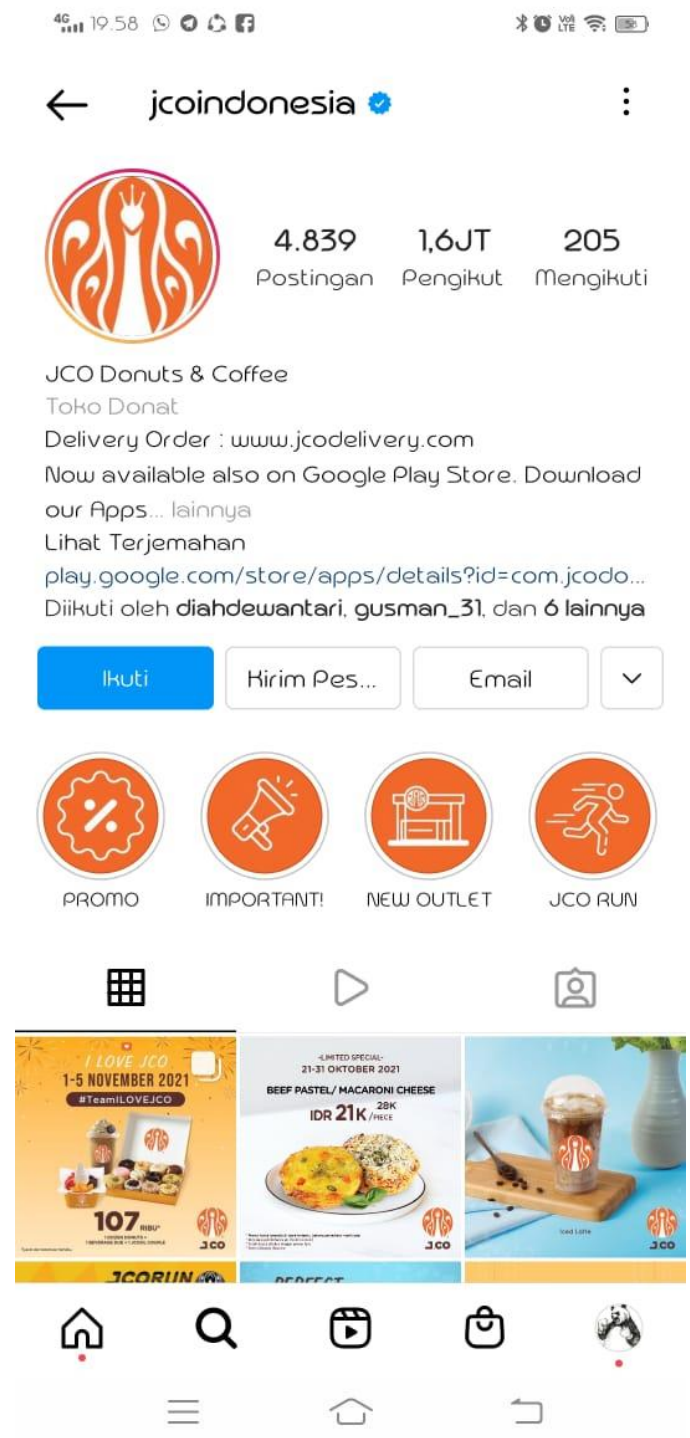

Gambar 1. Akun Instagram J-CO

Sumber : https://instagram.com/jcoindonesia?utm_medium=copy_link 


\section{CFC}
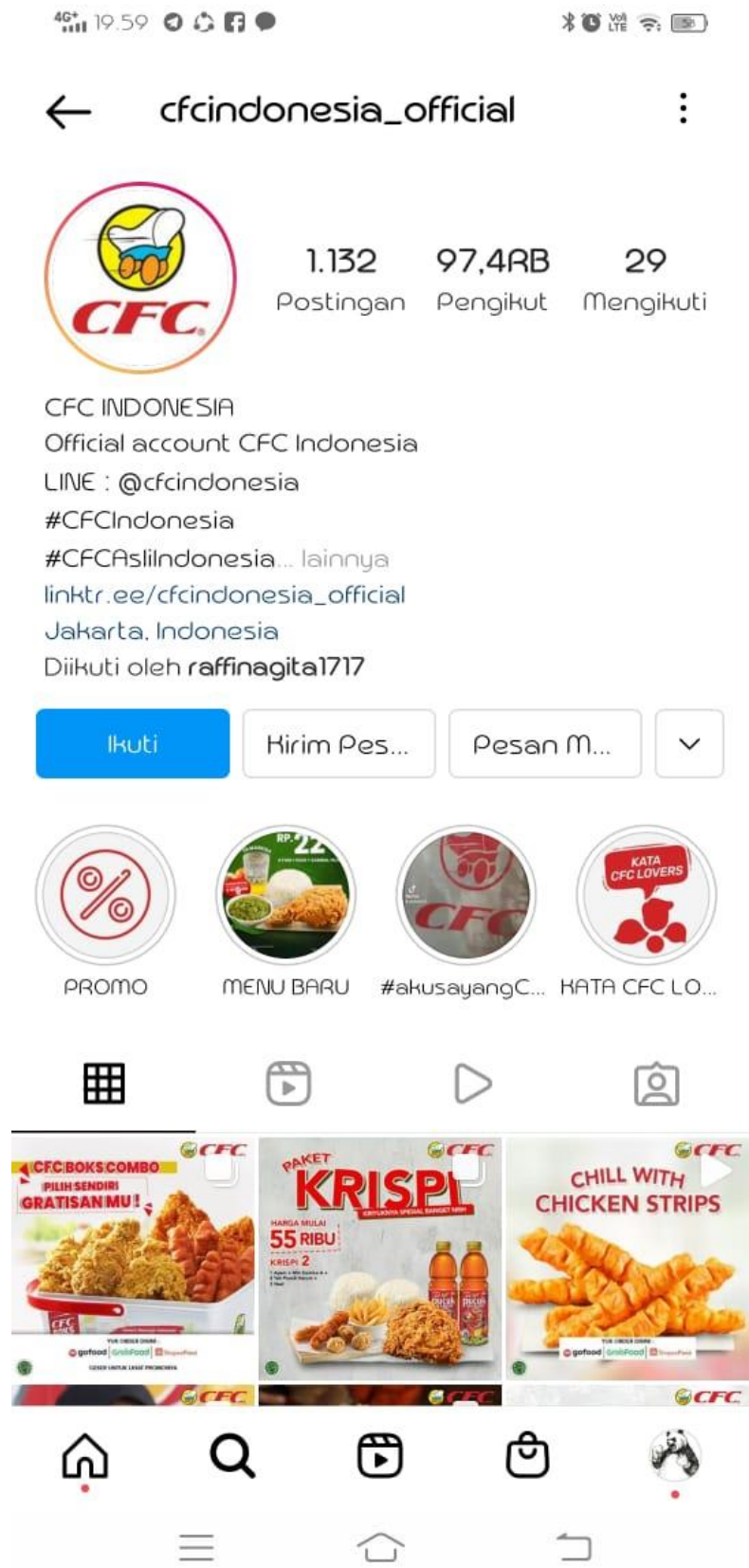

Gambar 2. Akun Instagram CFC

Sumber : $\underline{\text { https://instagram.com/cfcindonesia_official?utm_medium=copy_link }}$ 


\section{Krisbow}
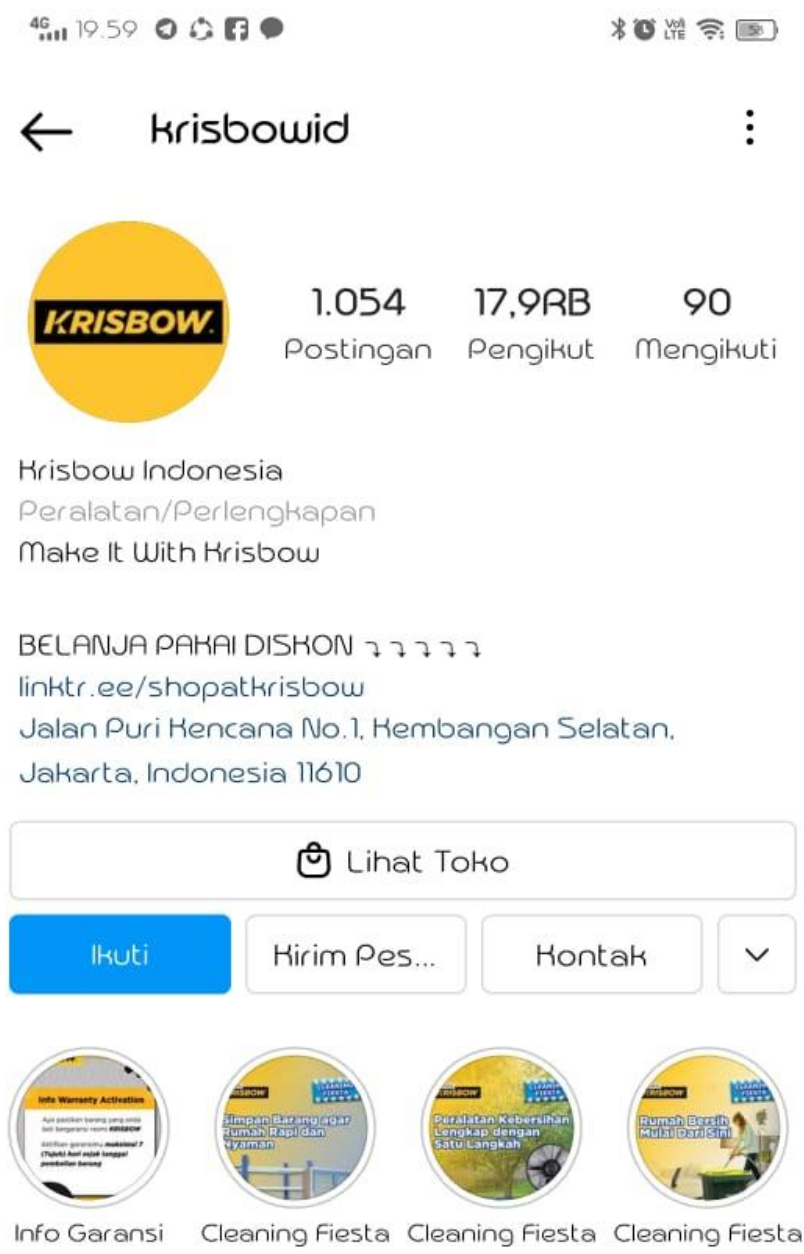

囲

D
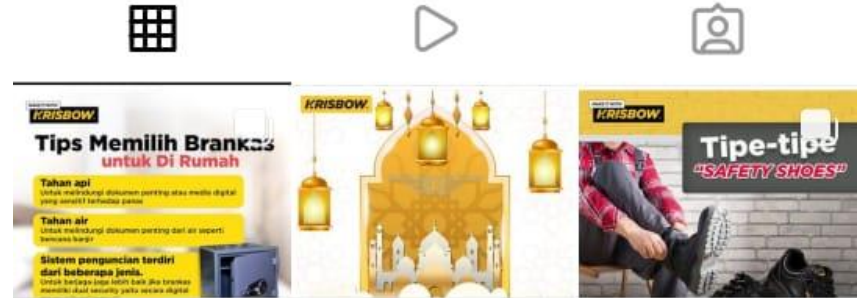

ณ

Q

Ð

๑

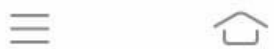

Gambar 3. Akun Instagram Krisbow

Sumber : https://instagram.com/krisbowid?utm_medium=copy_link 


\section{Men's Republic}

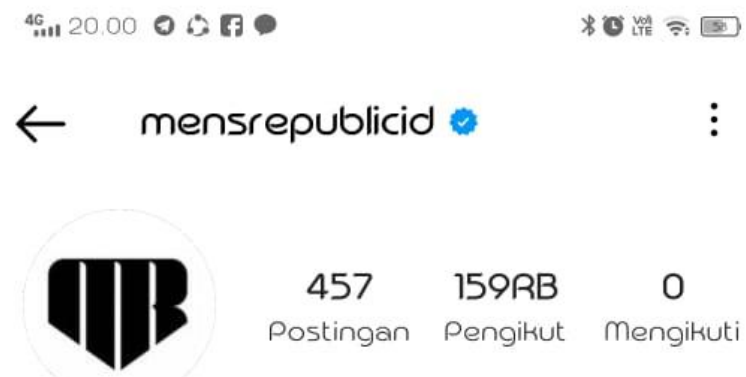

Mens Republic $\AA$

Thank you, gentlemen! 에

\#GoodbyemensRepublic

Lihat Terjemahan

www.mensrepublic.id/

Diikuti oleh bayupande01, tokobonekajumbo2, dan 4 lainnya

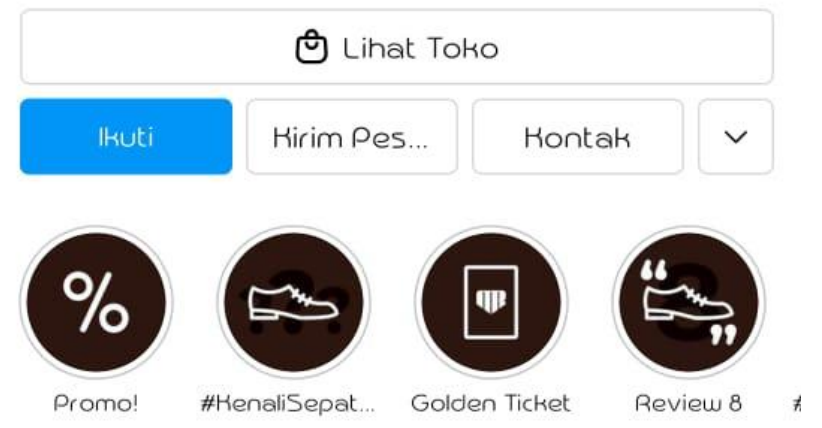

囲

$D$

0
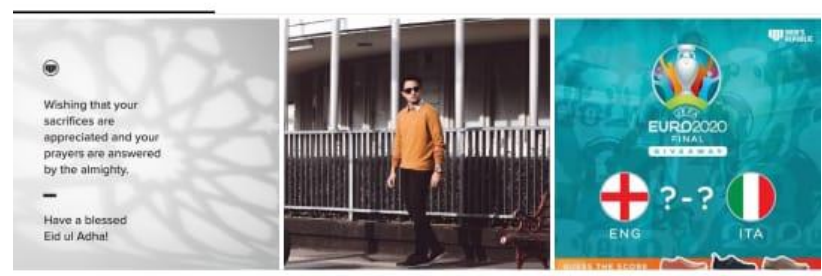

Q Q

因

అ

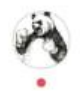

Gambar 4. Akun Instagram Men's Republic

Sumber : $h$ ttps://instagram.com/mensrepublicid?utm_medium=copy_link 


\section{Polytron}

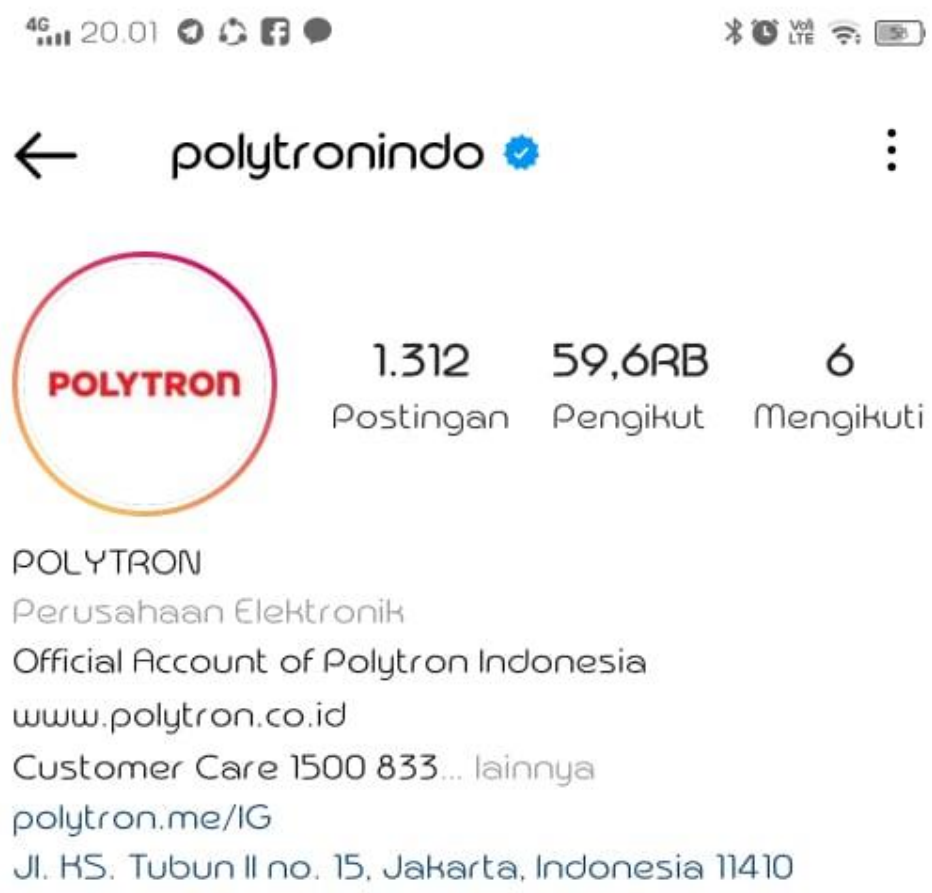

$\begin{array}{ccc}1.312 & 59,6 R B & 6 \\ \text { Postingan } & \text { Pengikut } & \text { mengikuti }\end{array}$

POLYTRON

Perusahaan Elektronik

Official Account of Polytron Indonesia

www.polytron.co.id

Customer Care 1500833 ... lainnya

polytron me/IG

JI. KS. Tubun II no. 15, Jakarta, Indonesia 11410

\section{@ Linat Toko}

\begin{tabular}{llll}
\hline Hirim Pes... Rontak & \\
\hline
\end{tabular}

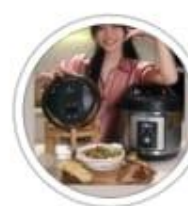

Air Fryer

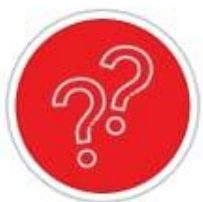

\#Info

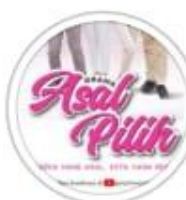

\#CustomerCa.

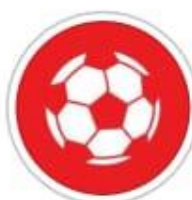

\#MolaPolytron

囲
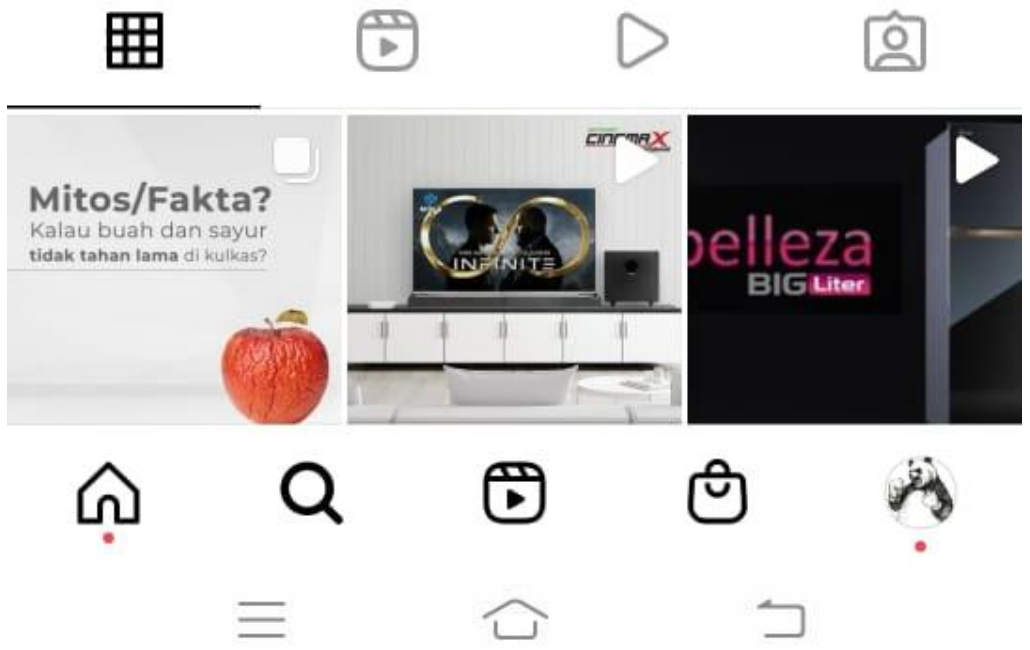

Gambar 5. Akun Instagram Polytron

Sumber : https://instagram.com/polytronindo?utm_medium=copy_link 
Dari kelima akun Instagram brand di Indonesia yang sering dikira brand luar negeri, peneliti menemukan nilai dari masing-masing variabel yang ada untuk menghitung rasio Image Comments to Image Likes Ratio dari setiap akun. Pada akun Instagram terdapat 7 variabel, diantaranya yaitu :

1. Followers

2. Following

3. Image Likes

4. Image Comment

5. Image Share

6. Image Views

7. Video Likes

8. Video Comments

9. Video Share

10. Video Views

Dari ketujuh variabel tersebut peneliti hanya fokus untuk menemukan hasil dari 2 variabel, yaitu :

1. Image Comment

2. Image Likes

Dari kedua variabel tersebut kemudian dianalisa sehingga menemukan nilai rata-rata dari variabel Image Comment dan Image Likes. Untuk menghitung nilai rata-rata dari variabel Image Comment dan Image Likes yaitu dengan cara mengambil jumlah Image Comment dan Image Likes pada masing masing akun Instagram kemudian di hitung sehingga menemukan nilai rata-rata dari masing-masing variabel. Berikut merupakan tabel nilai rata-rata dari masing-masing brand di Indonesia yang sering dikira brand luar negeri, yaitu : 
Tabel 1. Analisa Nilai Rata-Rata Nilai Variabel Image Comment dan Image Likes Akun Instagram Brand J-CO, CFC, Krisbow, Men's Republic, Polytron.

\begin{tabular}{|l|l|l|l|}
\hline No & Brand & Comment & Likes \\
\hline 1 & J-CO & 218,6 & 0 \\
\hline 2 & CFC & 0,5 & 0 \\
\hline 3 & Krisbow & 2,6 & 0 \\
\hline 4 & Men's Republic & 118,3 & 0 \\
\hline 5 & Polytron & 5,9 & 0 \\
\hline
\end{tabular}

Sumber : Pengolah Data Excel

Setelah menghitung nilai rata-rata tersebut, maka akan menemukan hasil akhir nilai rata-rata dari variabel Image Comment dan Image Likes.

Tabel 2. Nilai Variabel Pada Akun Instagram 5 brand di Indonesia yang sering dikira brand luar negeri.

\begin{tabular}{|l|l|l|l|l|l|}
\hline variabel & J-CO & CFC & Krisbow & Men's Republic & Polytron \\
\hline Comments & 218,6 & 0,5 & 2,6 & 118,3 & 5,9 \\
\hline Likes & 0 & 0 & 0 & 0 & 0 \\
\hline
\end{tabular}

Sumber : Pengolah Data Excel

Pada akun Instagram terdapat 17 rasio yang relevan digunakan untuk mengukur kredibilitas pada masing-masing akun. Namun pada penelitian kali ini hanya berfokus untuk menghitung Image Comment to Image Likes Ratio. Untuk menghitung kredibilitas dari masing-masing akun Instagram setiap brand, peneliti menghitung dengan cara : variabel 1 akan dibagi dengan variabel 2, sehingga ditemukan hasil analisisa dari rasio tersebut. 
Tabel 3. Hasil Perhitungan Rasio Akun Instagram

\begin{tabular}{|l|l|l|l|l|l|l|}
\hline No & Ratio & J-CO & CFC & Krisbow & Men's Republic & Polytron \\
\hline 1 & $\begin{array}{l}\text { Image Comment to } \\
\text { Image Likes Ratio }\end{array}$ & - & - & - & - & - \\
\hline
\end{tabular}

Sumber : Pengolah Data Excel

Image Comment to Image Likes Ratio memiliki karakteristik yang rendah, artinya sehingga dapat dikatakan, semakin rendah angka/nilai yang dihasilkan maka semakin baik performa dari akun tersebut. Untuk memberikan peringkat pada masing-masing Brand, peneliti memberikan angka tertinggi menurut jumlah keseluruhan comment karena jumlah total like pada semua brand tidak dilihatkan atau disembunyikan oleh admin akunnya Berikut merupakan tabel urutan nilai yang dihasilkan dari jumlah rata rata comment.

Tabel 4. Nilai Rasio Akun Instagram 5 brand di Indonesia yang sering dikira brand luar negeri

TABEL PERINGKAT

\begin{tabular}{|l|l|l|l|l|l|}
\hline Ratio & $\begin{array}{l}\text { J- } \\
\text { CO }\end{array}$ & CFC & Krisbow & Men's Republic & Polytron \\
\hline $\begin{array}{l}\text { Image Comment } \\
\text { To Image Likes }\end{array}$ & 1 & 5 & 4 & 2 & 3 \\
\hline
\end{tabular}

Sumber : Pengolah Data Excel

Dari Tabel Nilai Rasio Akun Instagram 5 brand di Indonesia yang sering dikira brand luar negeri dapat simpulkan bahwa brand J-CO mendapatkan nilai tertinggi untuk rasio Image Comment to Image Likes. Sedangkan akun Instagram brand CFC mendapatkan nilai terendah untuk rasio ini. Jadi, pada penelitian ini brand J-CO memiliki kredibilitas performa yang lebih baik dibandingkan dengan brand yang lainnya. 


\section{KESIMPULAN}

Tujuan dari penelitian ini adalah mengetahui kredibilitas performa dari Akun Instagram 5 brand di Indonesia yang sering dikira brand luar negeri menggunakan Image Comment to Image Likes Ratio. 5 brand tersebut diantaranya :J-CO, CFC, Krisbow, Men's Republic, dan Polytron. Dari kelima brand di indonesia tersebut dapat disimpulkan bahwa :

1. Peringkat pertama diraih oleh brand J-CO dengan nilai tertinggi yaitu 218,6

2. Peringkat kedua diraih oleh brand Men's Republic dengan nilai 118,3

3. Peringkat ketiga diraih oleh brand Polytron dengan nilai 5,9

4. Peringkat keempat diraih oleh brand Krisbow dengan nilai 2,6

5. Peringkat kelima diraih oleh brand CFC dengan nilai terendah yaitu 0,5 


\section{DAFTAR PUSTAKA}

https://www.goodnewsfromindonesia.id/2018/05/25/5-brand-di-indonesia-yang-sering-dikira-brandluar-negeri

https://id.wikipedia.org/wiki/Instagram

https://dianisa.com/pengertian-instagram/ 